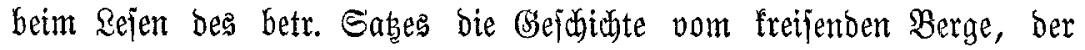

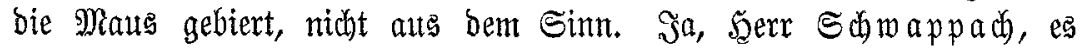
mirb fich aus biefen Mit teilungen "immerbin veridiedenes" lernen laffen

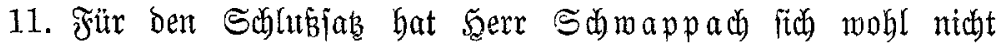
flar gemadht, mie ber Borberlag feiner lateintichen Flosfel lautet.

\title{
II. 3atitteilumaner.
}

\section{Die Windfälle in den franzöjiffhen Dogejen.}

(31. Sanuar bis 1. Februar 1902.)

Das 20. Şeft ber Revue des Eaux et Forets bringt einen $\mathfrak{\text { Trtiffel }}$

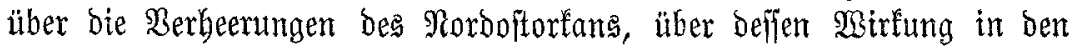
Deutichen 30 geien Dberforitmeifter $\Re$ ey bereits im 7 . Sefte bes Central=

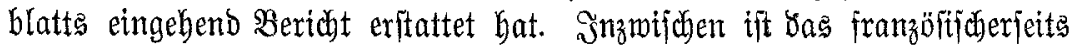
anfänglitu auf $771000 \mathrm{fm}$ angenommente Duantum Wintufälle auj

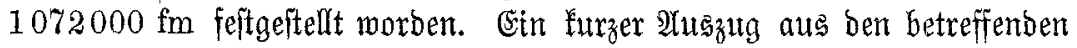
von Dberförfter Martin zut Fraize in etitem Bortrage behandelten

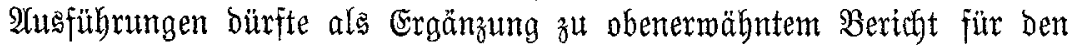
beutjchen Rejer nicht unintereffant jein.

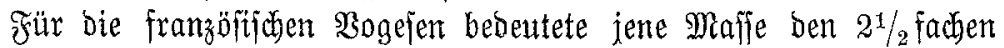
orbentlichen Sabregeinjollag; fie war alfo um fo mebr geeignet, einen

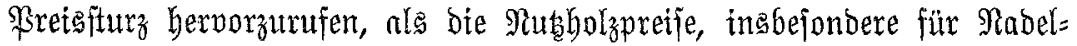
bolz, fobn im \&aufe von 1901 fallende Tendenz angenommen hatten.

IIm ber ßatffe tunlidjit entgegenzutreten, murben in Den Staats=

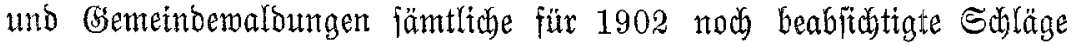
um 1 Sabre veribgoben und jowohl für bas 2 Uăbringen ber vorjährigen Schläge von feiten ber Säufer (Syjtem bes Berfaufs auj bem Stock bei $\mathfrak{A}$ ufarbeitung butrdy den Steigerer), als für Entribtung ber Steig=

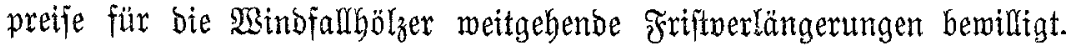
$\mathfrak{U} \mathfrak{m}$ aud bie fleineıt Şänoler zum Bieten zu veranlajien, wurben mehrere tleine soje gebildet.

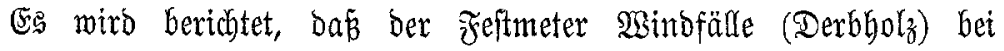

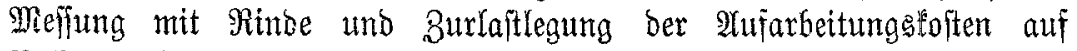

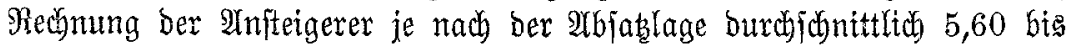

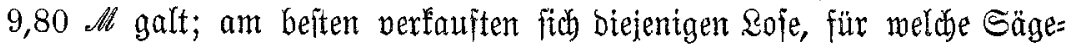
müblen zur Serfügung geitellt merben tonnten.

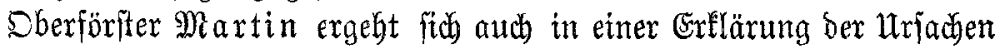
und begleitenden Umitände, vermöge welcher ber Sturm foldhe nerbeerenbe 


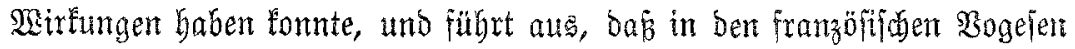

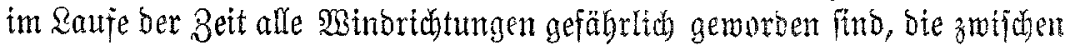

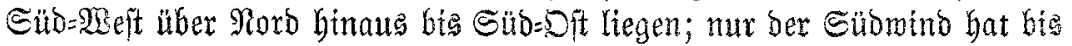

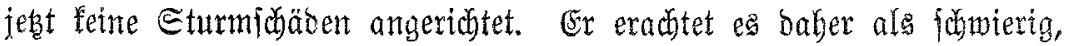
für bas Fortrilcen ber Saläge eine gegen ben Sturm beabfitutigte

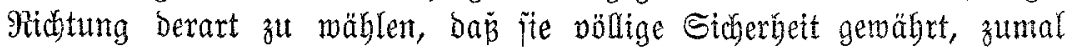
die anfänglidbe Winbrichtung burd) bas (sebirgggelänbe oft mejentlict abgeleitet wirb.

Sierzu möge bemerfft merben, baj es intmerbin Forttorte gibt, welche, foweit bas menichlide Gebäbtnis reicht, vermöge ibrer Rage gegen

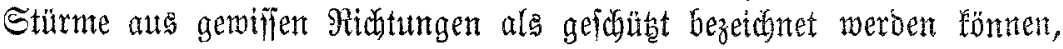
wogegen foldye aus anderen fichtlid bifter geidhadet habent. Die meitere Beobactung ber Fallridutung gemorfener bzölzer follte baher für bie einzeinen Forftorte fortgefeget uno in Jntereffe Der Sermertung gebucht merben.

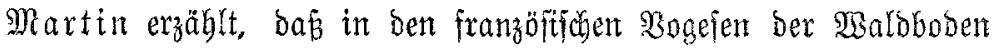

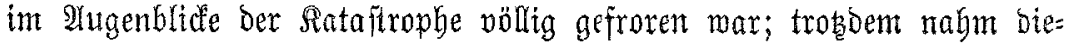
felbe io ungeheure Dimenitonen an.

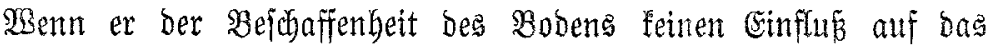

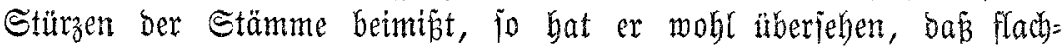
grünoige Böben bie Sturmgefabr erhöhen. Er will beobachtet baben, ba a auf demfelben Berghange bie fteilften Partien am meiten ver= fafont blieben unb fabreibt bies ber gleidgmäfitgeren Entwidfung ber räumiger ftebenden Stämme zu.

2uffallend finbet er bas ziemlich groß̌e Sontingent von Bublen unter den entwurzelten 2 Ultgölzern.

Ŝn ben frifoh angebauenen şeriünaungajolägent ift ber Sturm: fhaben am ärgften gemejen; wenn biejer in ben Femelmaldoungen minber in bie Ericheinung tritt, jo macht Martin andrerjeite barauf auf= merfian, baj jüngere, felbft gleichaltrige Sgotbmaldbeitänbe fo gut wie gar nidft gelitten baben. Sebenjalls gibt bie, Int unb waife ber $\mathfrak{B i n d}=$

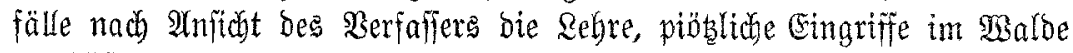
tunlichit zu vermetben, vielmefr fobn im Stangenbolzalter ganz all= mählicu auf eine räımigere Stellung binz̧uarbeiter. Dies foll Jrone

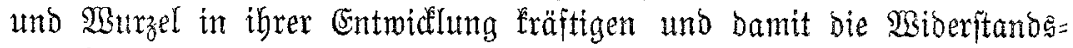
fäbigleit erbäben. Martin empfiehlt von biejem (selichtspunfte aus gleid) Boppe (früberer Diref́tor ber Foritifule Rancy) bie jogenamte Sopfourchforftung (éclaircie par le haut). Er meift barauf bin, bas

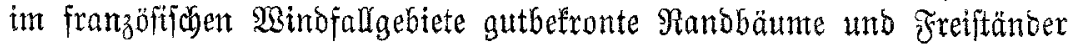
Dem Sturm getrobst baben. 
Wie jebr $\mathfrak{B}$ egeauffiebe int alten Sgoly, aud Rablfụläge in vor= liegenden Privatwaldungen den Sturmjchaden erböht haben, weitt er an ber Şand einiger Beipiele nach.

Dr. Ragl.

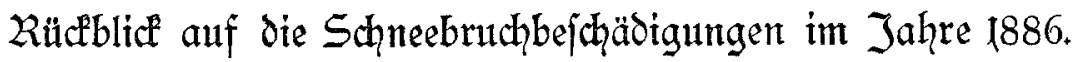

Den Fachgennffen, welche im Jahre 1886 bereits int Dienfte ftanden, wirb bas Inhbeil, weldjes ant 20. Dezentber 1886 und den folgenten

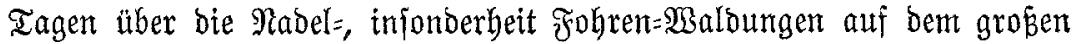
Gebiete von ber $\mathfrak{B f a l}_{z}$ bis zur Donaulinie hereinbrach, noch wohl in Erinnerung jein uno zeitlebens bleibent. Untgeheure Schneemaffen in

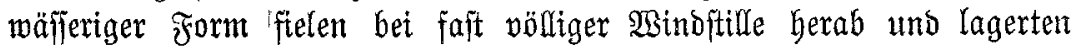
fith auf bie Beitände, von meldjen bie Jutngwädje durdh Schneebrud,

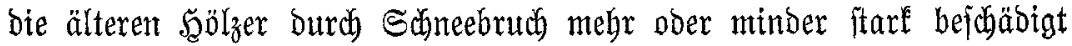
murben. Der Schaben war, fo fann behauptet werben, gröfzer, als je ein joldeer burd Sturmminde und Snjeftenbefdäbigungen verurfacht worben, auts bem Sorumbe, weil bie Beftände, joweit fie nicht ganz zum

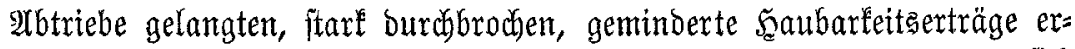
gaben, Das aus jungen ₹ohrenbeitänden angefallene Material, an firó

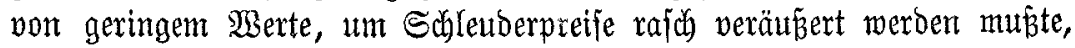
uno die Bodengäte an vielen Srten burd Bermilderung bes \$Bodens, Seibemuds 2c. eine grofie, aud für bie fonmende Gseneration nod fühl= bare Einbuße erlitten bat und ftellenweife nod fortwäbrend erleidet.

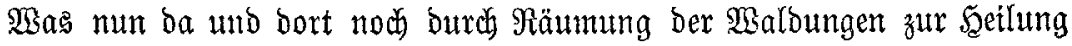
bes erlittenen Sabadeng geideben iit, ift fehr beadbtenswert namentlich für bie jüngeren Faddgenoffen, Denn, wie in ber 2. Seälfte bes 19. Salhr= Gunberts 3 febr ftarke Bejhäbigungen burch Sahneefall - 1861, 1868, 1886 - eingetreten finb, jo merben folde in ber 3 ufunft ntobt aus= bletben und nidht minderen Sdbaben bringen, atm fo mehr, als im Raufe

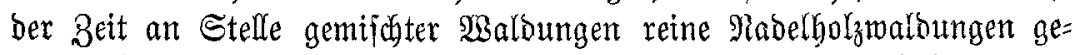
treten find und injonderbeit bie Fohrenwaldungen an attsbehnung ge= monnen baben.

Bon ben Fehlern, welche bei Behandlung Der bejoübtgten Beitände - idj bejdränfe mich htex auf reine Fogrenbeftänoe - gemadbt murden, fint folgente hervorzuheben:

1. $2 \mathfrak{u l z}_{z} \mathfrak{u}$ rajche Bejeitigung von Stänmen, weldye nicht ben ganzen sipfel perloren hatten, woburch ftellenmetje bie Schlubunter= brechungen verftärft wurben und ber $\mathfrak{S g}$ ozanfall unnötigerweije ver= 